\section{Initiation of complementary feeding and associated factors among children of age 6-23 months in Sodo town, Southern Ethiopia: Cross-sectional study}

Tefera Chane, ${ }^{1}$ Shimelash Bitew, 2 Tesfa Mekonnen, 3 Wubalem Fekadu ${ }^{3}$

1School of Public Health, Wollo University; ${ }^{2}$ School of Public Health, Wolaita Sodo University; ${ }^{3}$ School of Nursing and Midwifery, Bahir Dar University, Ethiopia

\section{Abstract}

Timely introduced complementary foods, which are appropriate for age, safe and nutrient dense are vital for child growth and development. The aim of the study was to identify associated factors that hampered timely introduction of complementary feeding practices among children 6-23 months. A community-based cross-sectional study was carried out. The data were collected from March 02-20, 2015 in seven-selected Kebeles of Wolaita Sodo town. Systematic sampling technique was employed to select 623 mothers/caregivers with children. The analysis was done using SPSS version 21 Principal component analysis was used to measure household economic status. Binary logistic regression was used to identify predictors of timely initiation of complementary feeding practice. The proportion of timely (at six months) introduction of complementary feeding was $71.2 \%$ [95\% CI: 66.4\%-75.3\%], and $25.5 \%$ [95\% CI: $21.7 \%$ $30 \%$ ] of children were experienced delayed introduction of complementary feeding. Variables like maternal education $[\mathrm{AOR}=0.33 ; 95 \%$ CI (0.14-0.78)], household economic status [AOR $=0.40 ; 95 \%$ $\mathrm{CI}(0.17-0.85)]$, history of child medical illness $[\mathrm{AOR}=0.63 ; 95 \%$ CI $(0.40-0.98)]$, early initiation of breastfeeding $[\mathrm{AOR}=2.59$; 95\% CI (1.02-7.35)] and having source of information about child feeding practices $[\mathrm{AOR}=0.41 ; 95 \% \mathrm{CI}(0.24$ $0.73)$ ] were identified as independent predictors of introduction of complementary foods at the age of six months. The study came up with nearly three-fourth of children were initiated complementary food just at six months of age. It is not much higher than the target of the current national health sector development program. Maternal illiteracy, low socioeconomic status, presence of medical illness and lack of source of information about complementary feeding practices were associated with timely initiation of complementary feeding. Unreserved support and encouragement should be made to raise level of timely introduction of complementary foods and to diminish delayed introduction of complementary food.

\section{Introduction}

Complementary feeding is the process of giving other food in addition to breast milk from the age of 6 months (or to an appropriate breast milk substitute in nonbreastfed infants). During the complementary feeding period (6-24 months), breastfeeding continues to significantly contribute to food and fluid security. Non-breastfed infants need support to make up the nutritional shortfall. Links with food security programmes are essential to support complementary feeding. ${ }^{1}$

An appropriate diet is a critical component for proper growth and development of children. The first two years of life are a critical window for ensuring optimal child growth and Nutritional deficiencies during this period can lead to impaired cognitive development, compromised educational achievement and low economic productivity which become difficult to reverse later in life. ${ }^{1}$ Improving infant and young child feeding (IYCF) practices in children 0-23 months of age is therefore critical to improve nutrition, health and development. ${ }^{2}$

Scientific evidence indicates that inappropriate feeding practices can have profound consequences for the growth, development and survival of infants and children. Appropriate complementary feeding (CF) entails; introduction of complementary foods at 6 months with continued breastfeeding up to at least 2 years and beyond, age appropriate feeding frequency and consumption of a diverse diet. ${ }^{3}$

In areas with poor food or water hygiene, early introduction of complementary foods is associated with increased morbidity for diarrhoeal diseases. ${ }^{3,4}$ Too long a delay in introducing appropriate complementary food may, however, lead to nutritional deficiencies of Iron, Zinc, calcium and sometimes vitamin A . Reports showed that 19 per cent of all under-5 deaths in the developing world could be prevented by appropriate CF. Even with optimum breast feeding children will become stunted if they do not receive sufficient quantities of quality complementary foods after six months of age. ${ }^{4}$ According to the Ethiopian Demographic and Health Survey 2011,
Correspondence: Tefera Chane, School of Public Health, Wollo University, P.O. Box: 1145, Northern Ethiopia.

Tel.: +251911587075

E-mail: teferachane@gmail.com

Key words: Timely initiation; complementary feeding factors; 6-23 months children.

Acknowledgments: our deepest gratitude goes to data collectors, kebeles leaders and Wolaita Sodo health center manager for his cooperation starting from the beginning till the end of data collection time. The last but not the least, our heartfelt thanks goes to Wolaita Sodo town residents particularly the respondents.

Funding: Wolaita Sodo University provided the financial support for the research project. But the University has no any role in the design of the study and collection, analysis, and interpretation of data and in writing the manuscript.

Contributions: TC: Initiated the research, wrote the research proposal, conducted the research, did data entry and analysis and wrote the manuscript. SB: Involved in the write up of the methodology of proposal and research work. TM: Contributed in the write up of proposal and write up of the manuscript. WF: participated in the write up of the methodology of proposal and research work. All are equally contributed.

Conflict of interests: the authors declare that they have no conflict of interests.

Received for publication: 24 May 2017.

Revision received: 4 October 2017.

Accepted for publication: 18 October 2017.

This work is licensed under a Creative Commons Attribution NonCommercial 4.0 License (CC BY-NC 4.0).

CC Copyright T. Chane et al., 2017

Licensee PAGEPress, Italy

Pediatric Reports 2017; 9:7240

doi:10.4081/pr.2017.7240

timely initiation of complementary feeding in Ethiopia at the 6th month was only $51 \% .5$ It is also documented that poor infant feeding practice which is poor breast feeding and poor complementary feeding contribute to $24 \%$ of infant deaths. ${ }^{6}$

Introducing solid foods into an infant's diet is recommended at about six months because at that age breast milk is no longer adequate in meeting a child's nutritional needs particularly energy, protein and micronutrient requirements to promote optimal growth.4,7 So, locally available foods that are rich in both macronutrient and micronutrient, hygienically prepared and suitable to eat need to be provided. During 
the transitional period when complementary foods are being introduced, on-demand and frequent breastfeeding should continue to ensure that infants receive all the benefits of breastfeeding. ${ }^{8}$

Exclusive breastfeeding for six months followed by timely initiation of appropriate complementary feeding with continued breastfeeding for the first year of life could avert $13 \%$ of the more than 10 million deaths among children under 5 every year. Regardless of the policy and strategies adopted by the Ethiopian Ministry of Health, the change seen in the practice of the timely initiation of complementary feeding from 2005 to 2010 was insignificant. 9

Large proportions of women in Ethiopia do not practice appropriate breastfeeding and complementary feeding behaviour for their children. ${ }^{7}$ According to 2012 the Ethiopian Demographic Health Survey report, $27 \%$ of mothers provide water, butter, and various types of food to feed their children, thereby reducing the percentage of exclusively breast-feed and increasing the percentage of receiving complementary food at very young age. ${ }^{10}$

Although breastfeeding is one of the components of Primary Health Care in Ethiopia, a wide range of harmful infant feeding practices are documented even after the implementation of infant and young child feeding guideline. In Ethiopia, limited scientific data are found concerning about introduction of complementary feeding practices. ${ }^{8} 9$ However, no studies are documented about complementary feeding patterns and its associated factors in children 6-23 months of age in the study area. Therefore, this study aims to assess the introduction of complementary feeding practices and associated factors among 6-23 months of age in Wolaita Sodo, southern Ethiopia.

\section{Materials and Methods}

\section{Study design and area}

A community based cross-sectional study design was conducted at Wolaita Sodo town. The town is located at $315 \mathrm{~km}$ from the capital city. The town is administratively structured by 11 kebeles and have a total population of 110,660 of which 54,275 are males and 56,385 are females. Out of all female population 25,784 of them are women in the reproductive age group. About $14 \%$ of the total population are children 6-59 months of age. The town has two hospitals, three health centres, 16 health posts and 16 drug stores. The study period was from March 2-20, 2015.

\section{Source and study populations}

Mothers or caregivers of children 6-23 months of age who reside in Wolaita Sodo town were the source population. Whereas, mothers/care givers of children 6-23 months who had been inhabited in the selected Kebeles were considered as study populations.

\section{Inclusion and exclusion criteria}

Mothers/caregivers of children 6-23 months of age who have been residents of the town and have ever breastfed in the selected Kebeles were included in the study. However, mothers or caregivers who were seriously ill, had mental problem or unable to communicate were excluded.

\section{Sample size determination and sam- pling procedure}

The sample size was determined using single proportion population formula, by taking the proportion of early introduction of complementary feeding as $42.9 \%$ in Jimma Arjo, 10 5\% level of significance, 1.5 as design effect by considering the presence of variations between the districts and at the household level and 5\% as margin of error and adding $10 \%$ as non-response rate the final sample size was 623 .

Multi-stage sampling technique was employed to capture the study participants. Out of eleven Kebeles (lowest administrative unit), seven Kebeles were selected by lottery method. Household census was conducted to identify mothers/caregivers with 6-23 months of children. Then 1259 mothers/caregivers with 6-23 months of children were selected from the seven Kebeles. In order to obtain the sample size from each seven Kebeles proportionate allocation was done. Eventually, after obtaining the sampling fraction (every two sampling interval), mother/caregiver child pair was selected from each household using systematic sampling technique. The index child was taken in a case if there is more than one child per household.

\section{Operational definitions}

Early introduction of $C F$ : Proportion of breastfed children 6-23 months of age who had been introduced $\mathrm{CF}$ before 6 months of age. ${ }^{2}$

Timely initiation of $C F$ : Proportion of breastfed children 6-23 months of age who had just started giving CF exactly at 6 months of age. 2

Introduction of solid, semi-solid or soft foods: Proportion of infants 6-8 months of age who had received solid, semi-solid or soft foods during the previous day. ${ }^{11}$
Kebeles and Woreda: Kebele is to mean lowest administrative unit while Woreda is to say District.

\section{Data collection method and quality assurance}

The data were collected through interviewer-administered questionnaire to the mother/caregiver in face-to-face interviews. Mothers were asked specific questions to elicit information on complementary feeding practices, Health care services, morbidity, child and maternal socio-demographic and economic characteristics.

The WHO standard IYCF practices assessment questionnaire ${ }^{12}$ was used to collect information on initiation of complementary feeding practices. This questionnaire was standardized and validated and has been successfully used in a variety of circumstances in developing countries. The adopted questionnaires were further translated into Amharic language and finally transcribed into English.

Pre-test was conducted in $5 \%$ of the sample size of the mother/caregiver child pair in similar area other than the actual data collection site to establish accuracy of the questions and clarity and to determine the length of interviews. During pre-testing an effort was made to check for consistency in the interpretation of questions and to identify ambiguous items. After review of the instruments all suggested revisions were made before being administered in the actual study.

Ten data collectors who have BSc in nursing and three supervisors were recruited to participate in the study. The selection criteria for data collectors were based on those who had a first degree in any field and fluency in Wolaitigna and Amharic. The supervisors had masters of public health holder and had previous experiences of fieldwork supervision. Training was given for data collectors for two days one day for pretesting. To ensure the completeness and consistency of information during data collection, the investigators and supervisors were made a systematic crosscheck its completeness and errors on the spot.

\section{Data management and analysis}

The investigators with an experienced data clerk were entered the data using Epi Data version 3.02 and exported to STATA version 12.0 for analysis. Data cleaning was performed to check for accuracy, consistencies, and missing values.

Descriptive statistics (frequency, mean, median, standard deviation and percentage) were used to describe Socio-demographic and economic characteristics of the study 
population and complementary feeding practices. Exploratory data analysis was done to check the presence of influential outliers, missing values and distribution of data for continuous variables.

Principal component analysis was done to construct the household wealth index. The indicator variables used for wealth index construction that fulfil the requirement of factor analysis were telephone, table, chair, refrigerator and electric mitad. Varimax rotation was used. The communality of each variable was greater than 0.53 ; Kaiser-Meyer-Olkin Measure of Sampling Adequacy was 0.58 and the significance of Bartlett's Test of Sphericity was less than 0.0001 . The cumulative proportion of variance criteria was met with two components which was $66.80 \%$. Split sample validation was done and none of communality's of the variable in each split was below 0.5. Reliability test was also considered with Cronbach's Alpha value of 0.69. Presence of outliers for factor scores and the presence of complex structure was also assessed. Finally, wealth index was categorized as poor, medium and rich.

Initiation of complementary food was dichotomized into 0 as no and 1 as yes. Binary logistic regression was done to see the crude association between the independent variables and the dependent variable and the strength of association was expressed in odds ratio (OR). Multivariable logistic regression analysis was done through entry methods of likelihood ratio technique to control the effects of confounding and to identify predictors of complementary feeding practices. A P value of $<0.05$ was used as the criterion for statistical significance.

\section{Results \\ Socio-demographic characteristics of participants}

There were 611 mothers/ caregivers with children 6-23 months, which constitutes $98.1 \%$ of response rate. From all participants, 605(99\%) of them were biological mothers. The mean age of mothers/caregivers was 26.7 years with \pm 4.8 years of standard deviation and the median age was also 26 years. More than halve $(65 \%)$ of the respondents' occupational status were found to be as house wives; and about onefourth of the participants $(26 \%)$ were completed grade ten and above but $11.5 \%$ of mothers/caregivers had no education.

Concerning about maternal empowerment or gender role in the household, 399 $(65.3 \%)$ of mothers had the primary respon- sibility of providing food for the household; only $10.3 \%$ of mothers/caregivers had the power to decide how household income is used. However, fathers $(77.6 \%)$ played the predominant role in how family income was used and almost all mothers/ caregivers (97.5\%) usually decided on what food to be cooked each day in the household.

Household economic status was computed. Surprisingly, more than two third of the households $(70.9 \%)$ were found in the poor category where as one fifth of the respondents $(17.3 \%)$ were under rich classification category (Table 1).

\section{Child characteristics}

Among all children in the age of 6-23 months, 351(57.4\%) were boys and the rest were girls. The mean age of children was 13.8 months with ( $\pm 4.9 \mathrm{SD})$ and the median age was 13 months. Children in the age range of $12-18$ months constituted $40.8 \%$ of the rest age groups. The proportion of children whose mothers had antenatal and postnatal care follows up were $97.4 \%$ and $76.8 \%$ respectively (Table 1 ). The percentage of children who were delivered at home was $6.1 \%$ and $93.9 \%$ were delivered at the health facility.

\section{Child feeding practices}

\section{Breast feeding}

Children who ever breastfed were 596 $(97.5 \%)$ and $564(92.3 \%)$ of them were still breast fed within 24 hours prior to the information given. Three fourth of the mothers $(76 \%)$ were initiated breastfeeding within one hour of giving birth. The proportion of children, who gained pre-lacteal feeding other than breast milk within the first three days of delivery, was $3.4 \%$.

\section{Initiation of complementary feeding prac- tices}

The proportion of mothers/caregivers who introduced solid, semi-solid or liquid foods to their children aged 6-8 months was $94.6 \%$. The magnitude of timely introduction of complementary feeding was found to be $71.2 \%$ [95\% CI: $66.4 \%-75.3 \%$ ]. In other hands, the proportion children who gained complementary food before six months were $3.3 \%$ [ $95 \%$ CI: $2.1 \%-5 \%$ ].

The proportion of 6-8 months of breastfed children who fed two or more times per day was $65.2 \%$ and for $9-23$ months of breastfed children who fed three or more times per day was $70.2 \%$. About $69.3 \%$ of breastfed children were fulfilling the requirement of minimum meal frequency. On the other hand, $53.3 \%$ of $6-23$ months of non- breastfed children were fed four or more times per day. However, the overall proportion of six to twenty three months of children who fulfilled the requirement of minimum meal frequency was $68.9 \%$.

\section{Factors associated with timely introduc- tion of complementary foods}

In Bivariate logistic regression analysis, timely introduction of complementary feeding showed statistically significant association with economic status of the household, child sex, attending antenatal care (ANC) follow up, early initiation of breastfeeding and had a source of information about child feeding practices. Nevertheless, after controlling the effect of the rest variables in multivariable logistic regression, maternal educational status and history of child medical illness were found to be statistically significant predictors of introduction of complementary food just at six months of age.

Generally, variables like maternal education, household economic status, history of child medical illness, early initiation of breastfeeding and having a source of information about child feeding practices were identified as independent predictors of introduction of complementary foods at the age of six months. Compared to mothers/caregivers whose educational status was above grade ten, illiterate mothers were $67 \%$ less likely to introduce complementary foods at 6 months $[\mathrm{AOR}=0.33$; $95 \%$ CI (0.14-0.78)]. Initiation of breastfeeding within one hour of delivery had a moderate positive statistical association with the timely introduction of complementary foods $[\mathrm{AOR}=2.59$; 95\% CI (1.027.35)]. However, having a history of child medical illness and mother/caregivers having no source of information about child feeding practices were negatively associated with the timely introduction of complementary feedings $[\mathrm{AOR}=0.63 ; 95 \% \mathrm{CI}$ $(0.40-0.98)]$ and $[\mathrm{AOR}=0.41 ; 95 \% \mathrm{CI}$ (0.24- 0.73$)]$ respectively (Table 2 ).

\section{Discussion}

The study revealed that the proportion of introduction of solid, semi-solid or liquid foods was $94.6 \%$ in mothers/caregivers children aged 6-8 months. This shows greatest achievements as compared to report from IYCF programming for nutrition outcomes that depict the percentage of introduction of complementary foods in Niger (62\%), Indonesia (87\%), Malawi $(83 \%)$, Kenya (81\%), and Congo DR $(81 \%) .13$ The overall percentage of timely introduction of complementary foods at six months of age was found to be $71.2 \%$ (95\% CI of $66.4 \%-75.3 \%$ ) in 6-23 months of chil- 
Table 1. Shows socio-demographic, economic and other characteristics of the participants reside in Wolaita Sodo town, Ethiopia, May 2015.

$\begin{array}{lcc}\text { Variables } & \text { Frequency Percent } \\ \text { Household head } & & \\ \text { Male } & 570 & 93.3 \\ \text { Female } & 41 & 6.7 \\ \text { Maternal and caregivers age (years) } & \\ 15-19 & 18 & 3.0 \\ 20-24 & 166 & 27.2 \\ 25-29 & 263 & 43.0 \\ 30-34 & 109 & 17.8 \\ \geq 35 & 55 & 9.0\end{array}$

Maternal relation with child

$\begin{array}{lll}\text { Mother } & 605 & 99.0\end{array}$

Caregiver

$6 \quad 1.0$

Marital status

Single

Married

$3 \quad 0.5$

Divorced

$577 \quad 94.4$

Widowed

$22 \quad 3.6$

Household head occupation

House wife

Government employee $\quad 184 \quad 30.1$

Daily worker $\quad 144 \quad 23.6$

Private worker $\quad 253 \quad 41.4$

Maternal occupation

Housewife

Private

397

65.0

Government

$91 \quad 14.9$

$123 \quad 20.1$

Educational status of woman

Illiterate

Grade 1-8

$70 \quad 11.5$

Grade 9-10

218

11.5
35.7

Above 10

$164 \quad 26.8$

Wealth index

$\begin{array}{lll}\text { Poor } & 433 & 70.9\end{array}$

Middle (medium) $\quad 72 \quad 11.8$

$\begin{array}{lll}\text { Rich } & 106 & 17.3\end{array}$

Decide how income used

$\begin{array}{lll}\text { Father } & 474 & 77.6\end{array}$

Mother/caregiver $\quad 63 \quad 10.3$

$\begin{array}{lll}\text { Both } & 74 & 12.1\end{array}$

Responsibility to give food

$\begin{array}{lll}\text { Father } & 178 & 29.1 \\ \text { Mother } & 399 & 65.3\end{array}$

$\begin{array}{lll}\text { Both } & 8 & 1.3\end{array}$

Other relatives

Decide what food cooked $\quad 26 \quad 4.3$

$\begin{array}{lll}\text { Father } & 7 & 1.2\end{array}$

Mother/caregiver $\quad 596 \quad 97.5$

Both

8

Sex of child

Male $\quad 351 \quad 57.4$

$\begin{array}{lll}\text { Female } & 260 & 42.6\end{array}$

Age of child (in months)

$\begin{array}{lll}6-8 & 112 & 18.3\end{array}$

9-11

118

249

19.3

$12-18$

$132 \quad 21.6$

$19-23$

21.6

Birth order

First

241

39.5

$2^{\text {nd }}-3$ rd

280

45.8

$4^{\text {th }}$ and above

$90 \quad 14.7$

dren settled in Wolaita Sodo town. As WHO recommendation, introduction of complementary foods at six months of age was not satisfactory and it was lower than findings from northern Ethiopia (79.7\%) and India $(77.5 \%)^{14,15}$ but much higher than the national figure $(51 \%)$, Axum $(52.8 \%)$, Bangladesh (23.8\%), Nepal (50\%) and Mekele (62.8\%).16-19 In general speaking, the magnitude of introduction of complementary food has showed great advances in achievement of the target of the health sector development program four and much trustworthy to say encourage able figure for enhancement of better feeding practice. The reason why these discrepancies happened may be due the presence of variations in geographical location, socio-cultural practices, policies and economical status. Furthermore, there may be better and effective implementation of essential nutrition action towards the improvement of complementary feeding practice in the region.

In the other side, $3.3 \%$ of mothers/caregivers were identified to initiate introduction of complementary food to their child earlier than six months of age which is significantly lower than study conducted in Jimma Arjo (42.9\%), Nepal (40.3\%) and India $(25.2 \%) .15,18$ As compared to these findings, the result in this setting is negligible but will have a huge impact to increase the level of timely initiation of complementary feeding. In addition, early introduction of complementary food in areas where there is overwhelming of poverty like Ethiopia, will end up ill health. The reasons behind early introduction of complementary foods were the perception that breast milk is not enough, the presence of medical illness and lack of time to stay with their child or being busy at work. This may also show the presence of some gaps to create awareness about the importance and timing of comple-

\begin{tabular}{lcc}
\hline Variables & Frequency Percent \\
ANC follow up & & \\
Yes & 595 & 97.4 \\
No & 16 & 2.6 \\
PNC follow up & & \\
Yes & 469 & 76.8 \\
No & 142 & 23.2 \\
\hline
\end{tabular}

Place of delivery

Home without TBA $\quad 25 \quad 4.1$

$\begin{array}{lll}\text { Home with TBA } & 12 & 2.0\end{array}$

Government health facility $523 \quad 85.6$

$\begin{array}{lll}\text { Private health facility } & 51 & 8.3\end{array}$

Contraceptive use $(\mathrm{n}=605)$

$\begin{array}{lll}\text { Yes } & 493 & 81.0\end{array}$

$\begin{array}{lll}\text { No } & 112 & 19.0\end{array}$

History of medical illness

\begin{tabular}{lll} 
Yes & 223 & 36.5 \\
No & 388 & 63.5 \\
\hline
\end{tabular}

mentary foods through nutrition education at the grass root level.

Furthermore, the study identified potential factors that highly affect the level of timely introduction of complementary foods at WHO recommended age. Maternal education, household socioeconomic status, presence of childhood medical illness, early initiation of breastfeeding and having source of information about complementary feeding practices were scrutinized as independent predictors of timely introduction of complementary food. As compared to mothers/caregivers who achieving maximum schooling (ten and above), illiterate mothers/caregivers were less likely to initiate complementary food at six months of age. This finding is nearly consistent with findings from southern Ethiopia (Sidama zone), Northern Ethiopia (Mekele), Pakistan, South India and five European countries $14,15,19-21$ but finding from Nepal, Lebanon and Axum, north Ethiopia16,18,22 reports that educational status did not show statistical significance. This may be due to as educational status increase; better knowledge they have and easily aware of new information and put into practice. Similarly, compared to mothers/caregivers from rich households, women of middle socioeconomic class were $60 \%$ less likely to timely introduce complementary foods. Similar result is observed in South India. ${ }^{15}$

In contrast to the above, mothers who had initiated breastfeeding one hour soon after delivery were almost 3 times more likely to begin complementary foods at six months as opposed to mothers who initiated breastfeeding after 24 hours of delivery. The finding was supported by a survey conducted in Jimma Arjo, southwest Ethiopia. ${ }^{9}$ The reason may be mothers who initiated breastfeeding within one hour are more knowledgeable and aware of the value of feeding practices.

The probability of initiation of complementary foods at six months of age in children who had history of medical illness was nearly $40 \%$ less likely as compared to children who had not. In addition to this, mothers who had no source of information concerning about complementary feeding practice were less likely to introduce complementary foods at the recommended age as compared to their counterparts. The result was consistent with a study from South West Ethiopia. 9

However, the study faced some limitations. Recall bias may be introduced to estimate the exact age at which the child has begun complementary food from a wide range of targets (6-23 months) were used even efforts were made to minimize it by preparing the local calendar. The use of 24 
Table 2. Multivariable logistic regression analysis of factors associated with timely introduction of complementary feeding in children 6-23 months of age in Wolaita Sodo town, Ethiopia in 2015.

\begin{tabular}{|c|c|c|c|c|}
\hline Variables & $\begin{array}{l}\text { Introduction of } \\
\text { Timely, N (\%) }\end{array}$ & $\begin{array}{l}\text { feedingCrude OR } \\
\text { Untimely, N (\%) }\end{array}$ & $\begin{array}{l}\text { Adjusted OR } \\
(95 \% \mathrm{CI})\end{array}$ & $(95 \% \mathrm{CI})$ \\
\hline $\begin{array}{l}\text { Household head } \\
\text { Male } \\
\text { Female }\end{array}$ & $\begin{array}{l}403(70.7) \\
32(78.0)\end{array}$ & $\begin{array}{c}167(29.3) \\
9(22.0)\end{array}$ & $\begin{array}{c}0.68(0.32-1.45) \\
1.00\end{array}$ & $\begin{array}{c}0.30(0.06-1.02) \\
1.00\end{array}$ \\
\hline $\begin{array}{l}\text { Maternal age } \\
\leq 24 \text { years } \\
25 \text {-30 years } \\
\geq 31 \text { years }\end{array}$ & $\begin{array}{c}130(70.6) \\
234(69.0) \\
71(80.7)\end{array}$ & $\begin{array}{c}54(29.4) \\
105(31.0) \\
17(19.3)\end{array}$ & $\begin{array}{c}1.00 \\
0.93(0.63-1.37) \\
1.74(0 . .94-3.22)\end{array}$ & $\begin{array}{c}1.00 \\
1.30(0.75-2.14) \\
1.64(0.70-3.83)\end{array}$ \\
\hline $\begin{array}{l}\text { Marital status } \\
\text { Single } \\
\text { Married }\end{array}$ & $\begin{array}{c}25(73.5) \\
410(71.0)\end{array}$ & $\begin{array}{c}9(26.5) \\
167(29.0)\end{array}$ & $\begin{array}{c}1.13(0.52-2.48) \\
1.00\end{array}$ & $\begin{array}{c}0.32(0.10-1.43) \\
1.00\end{array}$ \\
\hline $\begin{array}{l}\text { House hold head occupation } \\
\text { House wife } \\
\text { Government employee } \\
\text { Daily worker } \\
\text { Private worker }\end{array}$ & $\begin{array}{l}21(70.0) \\
123(66.8) \\
109(75.7) \\
182(71.9)\end{array}$ & $\begin{array}{l}9(30.0) \\
61(33.2) \\
35(24.3) \\
71(28.1)\end{array}$ & $\begin{array}{c}0.91(0.40-2.08) \\
0.79(0.52-1.19) \\
1.21(0.76-1.94) \\
1.00\end{array}$ & $\begin{array}{c}0.55(0.20-1.54) \\
0.77(0.46-1.30) \\
1.01(0.56-1.81) \\
1.00\end{array}$ \\
\hline $\begin{array}{l}\text { Maternal occupation } \\
\text { House wife } \\
\text { Government employee } \\
\text { Private worker }\end{array}$ & $\begin{array}{l}277(69.8) \\
64(70.3) \\
94(76.4)\end{array}$ & $\begin{array}{l}120(30.2) \\
27(29.7) \\
29(23.6)\end{array}$ & $\begin{array}{c}1.00 \\
1.03(0.62-1.69) \\
1.40(0.88-2.24)\end{array}$ & $\begin{array}{c}1.00 \\
0.90(0.43-1.92) \\
1.53(0.85-2.76)\end{array}$ \\
\hline $\begin{array}{l}\text { Maternal education } \\
\text { Illiterate } \\
\text { Up to grade ten } \\
\text { Above grade ten }\end{array}$ & $\begin{array}{l}43(61.7) \\
277(72.5) \\
115(72.3)\end{array}$ & $\begin{array}{c}27(38.3) \\
105(27.5) \\
44(27.7)\end{array}$ & $\begin{array}{c}0.61(0.34-1.10) \\
1.01(0.67-1.53) \\
1.00\end{array}$ & $\begin{array}{c}0.33(0.14-0.78) \\
0.64(0.35-1.18) \\
1.00\end{array}$ \\
\hline $\begin{array}{l}\text { Wealth index } \\
\text { Poor } \\
\text { Middle } \\
\text { Rich }\end{array}$ & $\begin{array}{l}310(71.6) \\
44(61.1) \\
81(76.4)\end{array}$ & $\begin{array}{l}123(28.4) \\
28(38.9) \\
25(23.6)\end{array}$ & $\begin{array}{c}0.78(0.47-1.28) \\
0.50(0.25-0.93) \\
1.00\end{array}$ & $\begin{array}{c}0.76(0.42-1.40) \\
0.40(0.17-0.85) \\
1.00\end{array}$ \\
\hline $\begin{array}{l}\text { Child sex } \\
\text { Male } \\
\text { Female }\end{array}$ & $\begin{array}{l}236(67.2) \\
199(76.5)\end{array}$ & $\begin{array}{l}115(32.8) \\
61(23.5)\end{array}$ & $\begin{array}{c}1.00 \\
1.60(1.11-2.28)\end{array}$ & $\begin{array}{c}1.00 \\
1.40(0.91-2.14)\end{array}$ \\
\hline $\begin{array}{l}\text { Birth order } \\
\text { First } \\
\text { Second -third } \\
\text { Fourth and above }\end{array}$ & $\begin{array}{l}171(70.9) \\
196(70.0) \\
68(75.5)\end{array}$ & $\begin{array}{l}70(29.1) \\
84(30.0) \\
22(24.5)\end{array}$ & $\begin{array}{c}1.00 \\
0.96(0.66-1.40) \\
1.26(0.73-2.21)\end{array}$ & $\begin{array}{c}1.00 \\
0.94(0.57-1.55) \\
1.21(0.55-2.64)\end{array}$ \\
\hline $\begin{array}{l}\text { ANC follow up } \\
\text { Yes } \\
\text { No }\end{array}$ & $\begin{array}{c}428(71.9) \\
7(43.7)\end{array}$ & $\begin{array}{c}167(28.1) \\
9(56.3)\end{array}$ & $\begin{array}{c}3.30(1.21-8.99) \\
1.00\end{array}$ & $\begin{array}{c}1.72(0.44-6.79) \\
1.00\end{array}$ \\
\hline $\begin{array}{l}\text { PNC follow up } \\
\text { Yes } \\
\text { No }\end{array}$ & $\begin{array}{l}332(70.8) \\
103(72.5)\end{array}$ & $\begin{array}{l}137(29.2) \\
39(27.5)\end{array}$ & $\begin{array}{c}0.92(0.62-1.40) \\
1.00\end{array}$ & $\begin{array}{c}0.78(0.46-1.34) \\
1.00\end{array}$ \\
\hline $\begin{array}{l}\text { Place of delivery } \\
\text { Home delivery } \\
\text { Health facilities }\end{array}$ & $\begin{array}{c}17(45.9) \\
418(72.8)\end{array}$ & $\begin{array}{c}20(54.1) \\
156(27.2)\end{array}$ & $\begin{array}{c}1.00 \\
3.15(1.61-6.17)\end{array}$ & $\begin{array}{c}1.00 \\
1.98(0.80-4.93)\end{array}$ \\
\hline $\begin{array}{l}\text { History of medical illness } \\
\text { Yes } \\
\text { No }\end{array}$ & $\begin{array}{l}152(68.2) \\
283(72.9)\end{array}$ & $\begin{array}{l}71(31.8) \\
105(27.1)\end{array}$ & $\begin{array}{c}1.26(0.88-1.80) \\
1.00\end{array}$ & $\begin{array}{c}0.63(0.40-0.98) \\
1.00\end{array}$ \\
\hline $\begin{array}{l}\text { Early initiation of BF } \\
\text { Within 1hr } \\
\text { Within 24hrs } \\
\text { More than 24hrs }\end{array}$ & $\begin{array}{l}384(82.6) \\
42(32.6) \\
10(55.6)\end{array}$ & $\begin{array}{l}81(17.4) \\
87(67.4) \\
8(44.4)\end{array}$ & $\begin{array}{c}3.80(1.45-9.88) \\
0.40(0.14-1.05) \\
1.00\end{array}$ & $\begin{array}{c}2.59(1.02-7.35) \\
0.51(0.10-0.90) \\
1.00\end{array}$ \\
\hline $\begin{array}{l}\text { Source of information about } \\
\text { Yes } \\
\text { No }\end{array}$ & $\begin{array}{l}307(67.0) \\
127(83.6)\end{array}$ & $\begin{array}{l}151(33.0) \\
25(16.4)\end{array}$ & $\begin{array}{c}1.00 \\
0.40(0.25-0.64)\end{array}$ & $\begin{array}{c}1.00 \\
0.41(0.24-0.73)\end{array}$ \\
\hline
\end{tabular}

CF, complementary feeding. The italic values show statistical significant variables 
hrs of recall to assess dietary diversity and meal frequency may also bring a recall bias. The study also failed to correlate the importance of complementary feeding practice indicators with the nutritional status of children and estimation of adequacy of energy and nutrient intakes.

\section{Conclusion and recommendation}

Generally the study concluded that nearly three-fourth of children were initiated complementary food just at six months of age. It is not much higher than the target of the health sector development program four. The proportion was higher when the denominator stretches to 6-8 months, which was $94.6 \%$. As many organizations and individual survey reports shows that breast milk is enough, good and concentrated sources of nutrients for up to four to six months of age and then after should be complemented with complementary foods. Therefore, unreserved support and encouragement should be made to increase the level of timely introduction of complementary foods and to diminish delayed introduction of complementary food.

Maternal illiteracy, low socioeconomic status, presence of medical illness and lack of source of information about complementary feeding practices was observed to affect timely initiation of complementary feeding negatively. These were the main factors that restrict much more achievable of the level of introduction of complementary foods at six months. But mothers who had initiated breastfeeding within one hour of delivery were found to be positively related to beginning of complementary food at six months.

Based on the findings of this study, ministry of health $(\mathrm{MOH})$ in collaboration with the ministry of Education (MOE) should take steps to reduce illiteracy rates and improve on the socio-economic status among women in the reproductive age.

\section{For regional health bureau and zone health office}

Nutrition education should be delivered in good manner by giving especial emphasis on child feeding practices through health extension program and nutrition advocacy through the use of mass media. Health extension workers should be trained to provide health services at community level to reduce the prevalence of communicable disease and to improve the coverage of timely introduction of complementary feeding.

\section{Ethical considerations}

Ethical clearance was obtained from Wolaita Sodo University; research ethics review committee before conducting the survey. Then information sheet and informed consent were provided to the participants after giving clear and deep instructions about the aim of the study and were asked for signing written informed consent from the participants. Anonymous data were taken and the confidentiality of participants' information was secured.

\section{References}

1. The Sphere Project. Infant and young child feeding standard 2; 2011. Available from: http://www.spherehandbook.org/en/infant-and-youngchild-feeding-standard-2-basic-andskilled-support/

2. WHO. Global strategy for infant and young child feeding; 2010.

3. Martines J, Paul VK, Bhutta ZA, et al. Neonatal survival: A call for action. The Lancet 2005 26;365:1189-97.

4. Saxena V, Kumar P. Complementary feeding practices in rural community: A study from block Doiwala district Dehradun. Indian J Basic Appl Med Res 2014;3:P.358-63.

5. Centeral Statistical Agency. Ethiopia Demographic and Health Survey In Addis Ababa; 2011

6. Ethiopian Public Health Initiative. Essential Nutrition Actions to Improve the Nutrition of Women and Children in Ethiopia, Including Under Situations of Emergencies and HIV/and AIDs; 2004.

7. Ethiopian Federal Ministry of Health. Program Implementation Manual of National Nutrition Program (NNP). Addis Ababa, Ethiopia; 2008.

8. Tamiru D, Aragu D, Belachew $\mathrm{T}$. Survey on the introduction of complementary foods to infants within the first six months and associated factors in rural communities of Jimma Arjo. Int $\mathrm{J}$ Nutr Food Sci 2013;2:77-84.

9. Shumey A, Demissie M, Berhane Y. Timely initiation of complementary feeding and associated factors among children aged 6 to 12 months in Northern Ethiopia: an institution-based cross-sectional study BMC Public Health 2013;13:1050.

10. Centeral Statistical Agency. Ethiopia Demographic and Health Survey 2012. Addis Ababa, Ethiopia and Calverton,
Maryland; 2012.

11. WHO-IYCF. Indicators for Assessing Infant and Young Child Feeding practices: Part1 Conclusions of a consensus meeting held in Washington D.C., USA; 2008.

12. WHO. Indicators for assessing Infant and Young Child Feeding practices: Part 2: Measurement. Conclusions of a consensus meeting held in Washington D.C., USA; 2010.

13. WHO. Indicators for assessing infant and young child feeding practices: Part 3 Country Profiles; 2010.

14. Saaka M, Larbi A, Mutaru S, HoeschleZeledon I. Magnitude and factors associated with appropriate complementary feeding among children 6-23 months in Northern Ghana BMC Nutrition 2016;2:2.

15. Rao S, Swathi P, Unnikrishnan B, Hegde A. Study of complementary feeding practices among mothers of children aged six months to two years A study from coastal south India. Austral Med J 2011;4:252-7.

16. Yemane S, Awoke T, Gebreslassie M. Timely initiation of complementary feeding practice and associated factors among mothers of children aged from 6 to 24 months in Axum town, north Ethiopia. Int $\mathrm{J}$ Nutr Food Sci 2014;3:438-42.

17. Satija M, Sharma S, Chaudhary A, et al. Infant and young child feeding practices in a rural area of North India. Asian J Med Sci 2015;6:6.

18. Basnet S, Sathian B, Malla K, Koirala DP. Reasons for early or late initiation of complementary feeding: a study in Pokhara. Am J Public Health Res 2015;3:69-75.

19. Haile D, Belachew T, Berhanu G, et al. Complementary feeding practices and associated factors among HIV positive mothers in Southern Ethiopia. J Health Populat Nutr 2015;34:5.

20. Sonia S, Veit G, Silvia S, et al. Introduction of complementary feeding in 5 European Countries. J Pediatr Gastroenterol Nutr 2010;50:92-8.

21. Liaqat P, Rizvi MA, Qayyum A, et al. Maternal education and complementary feeding. Pak J Nutr 2006;5:563-8.

22. Batal M, Boulghourjian C, Akik C. Complementary feeding patterns in a developing country: a cross-sectional study across Lebanon. EMHJ 2010;16:2. 